\title{
Pharmacokinetics of pentopril in the elderly
}

\author{
A. RAKHIT ${ }^{1}$, G. M. KOCHAK ${ }^{1}$, V. TIPNIS ${ }^{1}$, P. RADENSKY ${ }^{2}$, \\ M. E. HURLEY ${ }^{2} \&$ R. WILLIAMS ${ }^{3}$ \\ ${ }^{1}$ Clinical Pharmacokinetics and Disposition and ${ }^{2}$ Clinical Research, Pharmaceuticals Division CIBA-GEIGY \\ Corporation, Ardsley, NY and Summit, NJ and ${ }^{3}$ Drug Studies Unit, University of California Medical Center, \\ San Francisco, CA, USA
}

1 The pharmacokinetics of pentopril in elderly subjects aged 70 to 75 years were compared with those of healthy young subjects aged 22 to 26 years.

2 There were no appreciable differences between the two groups in any of the pharmacokinetic parameters for pentopril derived from its plasma data $\left(C_{\max }, t_{\max }, \mathrm{AUC}\right.$ and $\left.t_{1 / 2}\right)$. 3 In contrast, the active metabolite CGS 13934 exhibited an increase in mean values of AUC by $56 \%$ in elderly compared to young. However, the difference was not statistically significant $(0.1>P>0.05)$. The variability was, however, significantly higher $(P<0.05)$ in the elderly group compared with young. The peak time for metabolite was also significantly delayed in elderly $(3.9 v s 2.5 \mathrm{~h})$. The mean half-life for metabolite however, was comparable for the two groups $(3.6 v s 3.9 \mathrm{~h})$.

4 Urinary analysis showed a significant decrease in renal clearance $\left(C L_{R}\right)$ with age for both pentopril (107 vs $203 \mathrm{ml} \mathrm{min}^{-1}$ ) and its active metabolite (116 vs $\left.205 \mathrm{ml} \mathrm{min}^{-1}\right)$.

5 Pharmacodynamic measurements of the renin-angiotensin system, in general, demonstrated a drug effect at $2 \mathrm{~h}$ with recovery almost to the basal value at $24 \mathrm{~h}$ except for plasma ACE activity at $24 \mathrm{~h}$ in the elderly.

6 Because of large variability and an increase in the mean AUC of active metabolite in elderly, greater caution may be necessary for dose selection in this group. However, no substantial difference in extent of drug accumulation is anticipated in elderly compared with young people based on the similarity in $t_{1 / 2}$ values.

Keywords pentopril pharmacokinetics elderly

\section{Introduction}

The ageing process has been shown to influence the kinetics of many drugs. The well-established reduction in renal function and associated decrease in excretion of drugs and their metabolites in the elderly often require dosage adjustments (Reidenberg, 1982). The effect of ageing on drug absorption, distribution and hepatic metabolism is, however, variable and often unpredictable (Crooks, 1983; Lamy, 1982). Age has been shown to cause decreased rate of elimi- nation for those benzodiazepines which are oxidized (Greenblatt et al., 1981; Klotz \& Muler-Seydlitz, 1979), but has very little influence on benzodiazepines that are primarily conjugated (Greenblatt et al., 1979, 1980). The effect of ageing on esterases which cause activation of prodrugs by hydrolysis is not well documented.

Pentopril is the prodrug ester of an active angiotensin converting enzyme (ACE) inhibitor,

*Current address and address for correspondence: Dr Ashok Rakhit, Clinical Biology, Research Department, Pharmaceuticals Division, CIBA-GEIGY Corporation, Summit, New Jersey 07901, USA 
CGS 13934, being developed for the treatment of hypertension and congestive heart failure. Pentopril, like enalapril, and other similar ACE inhibitors, is hydrolysed in vivo, to the active diacid metabolite, CGS 13934 (Chen et al., 1984). The efficacy of pentopril has been assessed, and this drug has been found to be an effective ACE inhibitor in humans (Jacot des Combes et al., 1983). Pharmacokinetics and pharmacodynamics of pentopril in young adults have recently been reported (Rakhit et al., 1986). Pentopril was found to be absorbed rapidly following zeroorder kinetics. About $20 \%$ of the administered dose was reported to be excreted as unchanged drug while $40 \%$ was excreted in the urine as the active metabolite. Plasma angiotensin converting enzyme activity as well as angiotensin I induced pressor response were found to be correlated with the metabolite concentration in plasma, rather than that of the prodrug pentopril Since hypertension and congestive heart failure are more prevalent in the older population, and pentopril has to be activated to form the active metabolite, the purpose of this study was to investigate the effects of ageing on disposition of both pentopril and its active metabolite.

\section{Methods}

\section{Study design}

Twelve male subjects were selected for the study. The group of young consisted of six healthy volunteers aged 22-26 years (mean: 23.3 (s.d. 1.4) years), while the elderly group consisted of six healthy volunteers aged 70 to 75 years (mean: 72.2 (s.d. 1.9) years). Inclusion criteria for both were: (a) normal healthy males whose body weights were within $\pm 15 \%$ of desirable values for height and body frame; (b) clinical laboratory tests and ECG being within the normal range or with minimal deviations determined to be clinically insignificant by the clinical investigator. Criteria for serum creatinine were $<1.4 \mathrm{mg} \mathrm{dl}^{-1}$ $\left(123 \mu \mathrm{moll}^{-1}\right)$ for subjects $18-35$ years and $<2.0$ $\mathrm{mg} \mathrm{dl}{ }^{-1}\left(175.6 \mu \mathrm{mol} \mathrm{l}^{-1}\right)$ for subjects 70 years and older. Except for the test drug, no other medication was permitted for 2 weeks preceding and for the duration of the study. Subjects were also not allowed to smoke, chew tobacco, consume alcohol, drink caffeine containing beverages or eat chocolate for 2 days before and during the active phase of the study. The protocol was approved by the Committee on Human Research of University of California at San Francisco Medical Center. Informed consent was obtained from all the subjects after explana- tion of the risks and inconveniences that could reasonably be expected.

Each subject received two $125 \mathrm{mg}$ capsules of pentopril on the study day. The drug was administered following a $10 \mathrm{~h}$ overnight fast. Breakfast was served $4 \mathrm{~h}$ after drug administration. Blood samples $(7 \mathrm{ml})$ were collected for plasma drug and metabolite analysis at scheduled intervals of 0 (pre-dose), $0.33,0.67,1,1.5,2,2.5,3,4,5,6$, $8,10,16$ and $24 \mathrm{~h}$ post dosing. Additional $30 \mathrm{ml}$ blood samples were taken before dosing, at 2 and $24 \mathrm{~h}$ post dosing to determine plasma angiotensin converting enzyme activity and different hormones of the renin-angiotensin system. Inulin clearance was estimated in each subject before drug administration to determine the individual renal function. Urine samples were collected for drug and metabolite assay at intervals of $0-6,6-12$ and $12-24 \mathrm{~h}$ post dosing. Blood samples for drug assay were collected in heparinized Vacutainer (Becton Dickinson) tubes, centrifuged, plasma separated and stored frozen until analysis. The total urine collected at any interval was measured and an aliquot stored frozen until analysis.

\section{Analysis of samples}

Plasma samples were analyzed for pentopril and its metabolites (CGS 13934) using an h.p.l.c. procedure (Rakhit \& Tipnis, 1984) while the urine samples were analyzed with a GC procedure (Tipnis \& Rakhit, 1985). The sensitivity limit for both pentopril and metabolite were $50 \mathrm{ng} \mathrm{ml}^{-1}$ in plasma and $1 \mu \mathrm{g} \mathrm{ml}^{-1}$ in urine samples.

\section{Analysis of data}

The pharmacokinetic evaluation of the plasma concentration data was performed using model independent methods. Elimination half-lives $\left(t_{1 / 2}\right)$ for pentopril and metabolite were calculated by least squares regression analysis of the terminal log-linear part of the plasma concentration $v s$ time curves. Areas under the curves (AUC) were calculated by the trapezoidal rule and extrapolated to infinity.

Oral pentopril clearance $\left(\mathrm{CL}_{\mathrm{po}}\right)$, metabolite clearance $\left(\mathrm{CL}_{m}\right)$ and renal clearance $\left(\mathrm{CL}_{\mathrm{R}}\right)$ were calculated as follows:

$$
\begin{aligned}
& \mathrm{CL}_{\mathrm{po}}=\mathrm{CL} / F=\text { Dose/AUC } \\
& \mathrm{CL}_{m}=F \cdot f_{m} \cdot \text { Dose/AUC }{ }_{m} \\
& \mathrm{CL}_{\mathrm{R}}=A e / \text { AUC }
\end{aligned}
$$

where $F$ is the bioavailable fraction, $f_{m}$ is the fraction of the systemic dose metabolised and $A e$ is the total amount of drug or metabolite excreted 
in the urine. For statistical analysis, the unpaired Student's $t$-test was used, $P<0.05$ being taken as the level of significance.

\section{Results}

\section{Pharmacokinetics}

Plasma concentration-time profiles for young and elderly subjects are shown in Figure 1 for pentopril and Figure 2 for the active metabolite. Age had little effect on any of the pharmacokinetic parameters of pentopril analyzed from the plasma data $\left(C_{\max }, t_{\max }\right.$, AUC and $t_{1 / 2}$; Table 1). Urinary excretion measurements, however, demonstrated a significant decrease $(P<0.05)$ in mean renal clearance of pentopril (elderly: $107 \mathrm{ml} \mathrm{min}^{-1}$ vs young: $203 \mathrm{ml} \mathrm{min}^{-1}$ ). The effect of age on the disposition of the active metabolite (CGS 13934) was apparent from the plasma data, since the mean $C_{\max }$ and AUC increased with age by $25 \%$ and $56 \%$, respectively (Table 2 ). In spite of a relatively large increase in mean values, these changes were not statistically significant $(P>0.05)$. The time for peak metabolite plasma concentration, how- ever, was prolonged to a significant extent (3.9 $v s 2.5 \mathrm{~h}$ ). The terminal half-life of the metabolite did not change significantly (3.57 vs $3.89 \mathrm{~h})$, although the renal elimination showed a significant decrease in elderly compared to young (116 vs $205 \mathrm{ml} \mathrm{min}^{-1}$ ) (Table 2).

\section{Pharmacodynamics}

Changes in plasma angiotensin converting enzyme (ACE), angiotensin I (AI) and aldosterone levels are shown in Figure 3. Plasma ACE activity decreased to almost zero at $2 \mathrm{~h}$ in both groups. Recovery of enzyme activity measured at $24 \mathrm{~h}$ was almost complete in young subjects while ACE activity was still inhibited to a significant extent $(P<0.05)$ in the elderly. In the young subjects, AI levels increased at $2 \mathrm{~h}$, as expected, while decreasing towards the basal value at $24 \mathrm{~h}$. In the elderly subjects, AI levels continued to increase even at $24 \mathrm{~h}$ after drug administration. There was, however, no statistically significant difference in plasma AI level at $24 \mathrm{~h}$ between two age groups. Changes in plasma aldosterone level were similar in both age groups; aldosterone level decreased at $2 \mathrm{~h}$ while recovering to almost the baseline value at $24 \mathrm{~h}$.

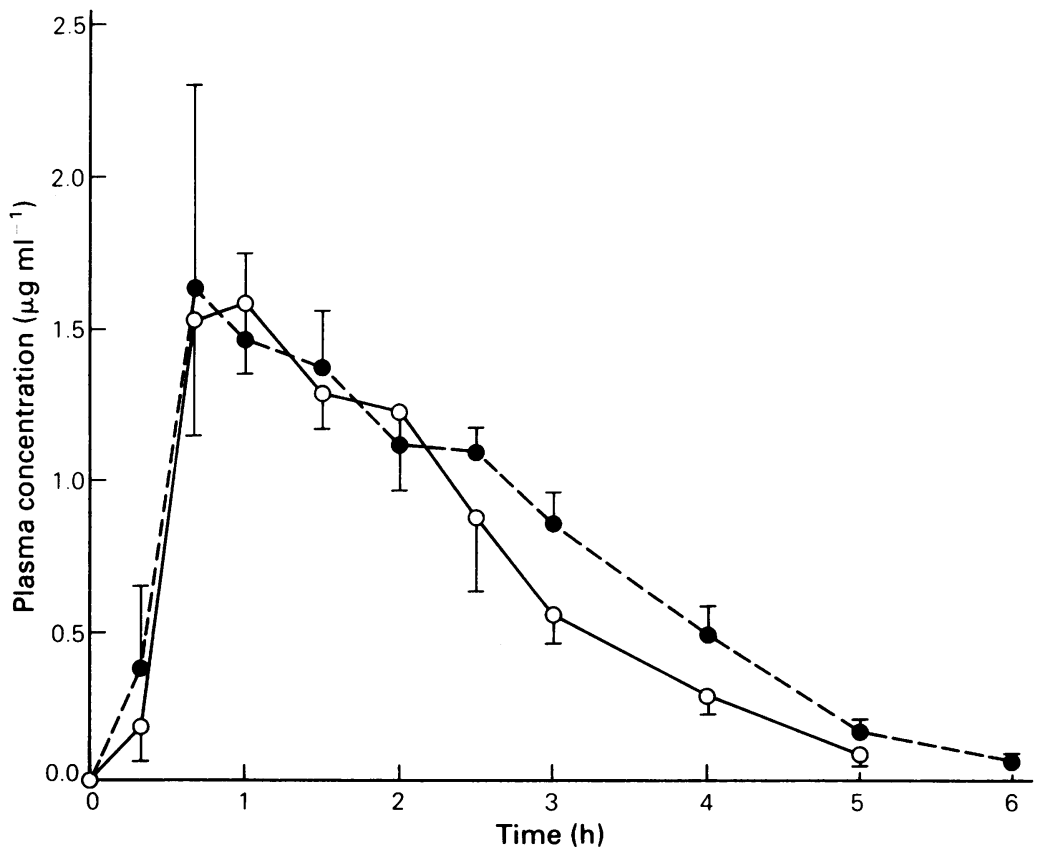

Figure 1 Mean ( \pm s.e. mean) plasma concentration-time profiles for pentopril in two age groups (O young, $\bullet$ elderly). 


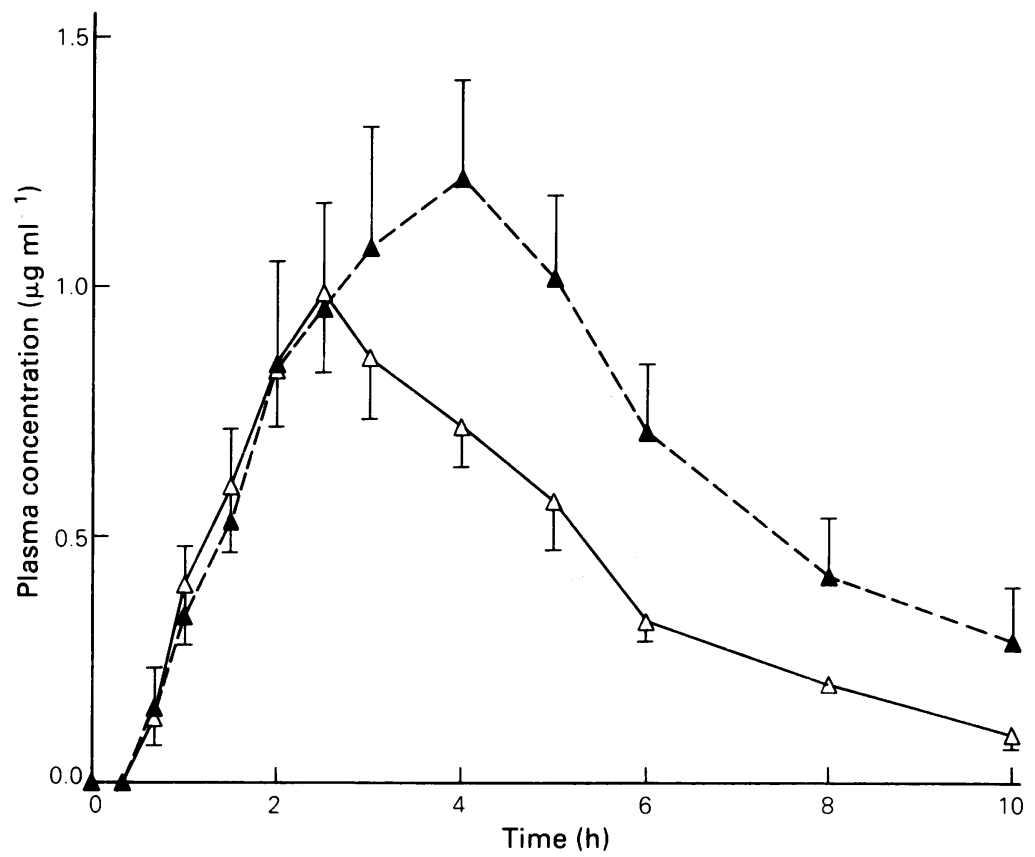

Figure 2 Mean ( \pm s.e. mean) plasma concentration-time profiles for metabolite in two age groups $(\triangle$ young, $\Delta$ elderly) following pentopril administration.

Table 1 Mean (s.d.) pharmacokinetic parameters of pentopril

\begin{tabular}{lccccccc}
\hline & $\begin{array}{c}\text { Age } \\
(\text { years })\end{array}$ & $\begin{array}{c}\mathrm{C}_{\max } \\
\left(\mu g \mathrm{ml}^{-l}\right)\end{array}$ & $\begin{array}{c}\mathrm{t}_{\max } \\
(h)\end{array}$ & $\begin{array}{c}\text { Terminal } \\
\text { half-life } \\
(h)\end{array}$ & $\begin{array}{c}A U C \\
\left(\mu g m l^{-1} h\right)\end{array}$ & $\begin{array}{c}C L_{R} \\
\left(\mathrm{ml} \mathrm{min}^{-1}\right)\end{array}$ & $\begin{array}{c}C L_{p o} \\
\left(l h^{-1}\right)\end{array}$ \\
\hline Young & 23.33 & 2.03 & 1.28 & 0.83 & 3.88 & 203 & 66.3 \\
& $(1.37)$ & $(0.63)$ & $(0.48)$ & $(0.31)$ & $(0.65)$ & $(55)$ & $(12.7)$ \\
Elderly & 72.17 & 2.08 & 1.22 & 0.95 & 4.60 & 107 & 57.7 \\
& $(1.94)$ & $(1.29)$ & $(0.62)$ & $(0.44)$ & $(1.11)$ & $(35)$ & $(16.9)$ \\
\% Difference & & $3 \%$ & $5 \%$ & $14 \%$ & $19 \%$ & $47 \%$ & $13 \%$ \\
Significance* & & $\mathrm{NS}$ & $\mathrm{NS}$ & $\mathrm{NS}$ & $\mathrm{NS}$ & $\mathrm{S}$ & $\mathrm{NS}$ \\
\hline
\end{tabular}

* Unpaired $t$-test, S means significant $(P<0.05)$ and NS means not significant $(P>0.05)$.

\section{Discussion}

The data in this study indicate that age did not affect the plasma concentration-time profile of pentopril, suggesting no overall effect of age on absorption and elimination of pentopril. The mean concentration-time profile for metabolite, however, showed an appreciable increase in both peak concentration (25\%) and AUC (56\%). In spite of such a large increase in AUC, the difference was not statistically significant $(0.1>P$ $>0.05)$. This is apparent from Figure 4 which shows a large interindividual variability in the elderly compared with the young. Statistical analysis showed a significant difference $(P<0.05)$ in variability of AUC between the two groups. Unlike AUC, the terminal half-lives of the active metabolite for the two age groups were quite comparable both in mean values and variance (Figure 5). One subject in each group showed a long terminal half-life $(8.0$ and $9.3 \mathrm{~h})$. This could be explained by the existence of a slower multiexponential terminal phase (Rakhit et al., 1986) which often is not detected because of the sensitivity limit of the analytical method $\left(50 \mathrm{ng} \mathrm{ml}^{-1}\right)$. However, the contribution of this slower terminal 
Table 2 Mean (s.d.) pharmacokinetic parameters of the active metabolite

\begin{tabular}{lccccccc}
\hline & $\begin{array}{c}\text { Age } \\
(\text { years })\end{array}$ & $\begin{array}{c}C L_{\text {in }} \\
\left(\mathrm{ml} \mathrm{min}^{-1}\right)\end{array}$ & $\begin{array}{c}\mathrm{C}_{\text {max }} \\
\left(\mu g \mathrm{ml}^{-1}\right)\end{array}$ & $\begin{array}{c}\mathrm{t}_{\max } \\
(h)\end{array}$ & $\begin{array}{c}\text { Terminal } \\
\text { half-life } \\
(\boldsymbol{h})\end{array}$ & $\begin{array}{c}A U C \\
\left(\mu g \mathrm{mlh}^{-1}\right)\end{array}$ & $\begin{array}{c}C L_{R} \\
\left(\mathrm{ml} \mathrm{min}^{-1}\right)\end{array}$ \\
\hline Young & 23.33 & 87.6 & 1.07 & 2.50 & 3.89 & 5.21 & 205 \\
Elderly & $(1.37)$ & $(29.7)$ & $(0.36)$ & $(0.32)$ & $(2.73)$ & $(1.26)$ & $(68)$ \\
& 72.17 & 65.7 & 1.33 & 3.92 & 3.57 & 8.14 & 116 \\
\% Difference & $(1.94)$ & $(27.9)$ & $(0.48)$ & $(0.80)$ & $(2.28)$ & $(3.76)$ & $(48)$ \\
Significance* & & $25 \%$ & $25 \%$ & $57 \%$ & $8 \%$ & $56 \%$ & $43 \%$ \\
\hline
\end{tabular}

* Unpaired $t$-test, $\mathrm{S}$ means significant $(P<0.05)$ and NS means not significant $(P>0.05)$.

** $0.05<P<0.1$; unequal variance $(P<0.05)$.

$+P=0.10$.

$\mathrm{CL}_{\text {in }}$, inulin clearance.
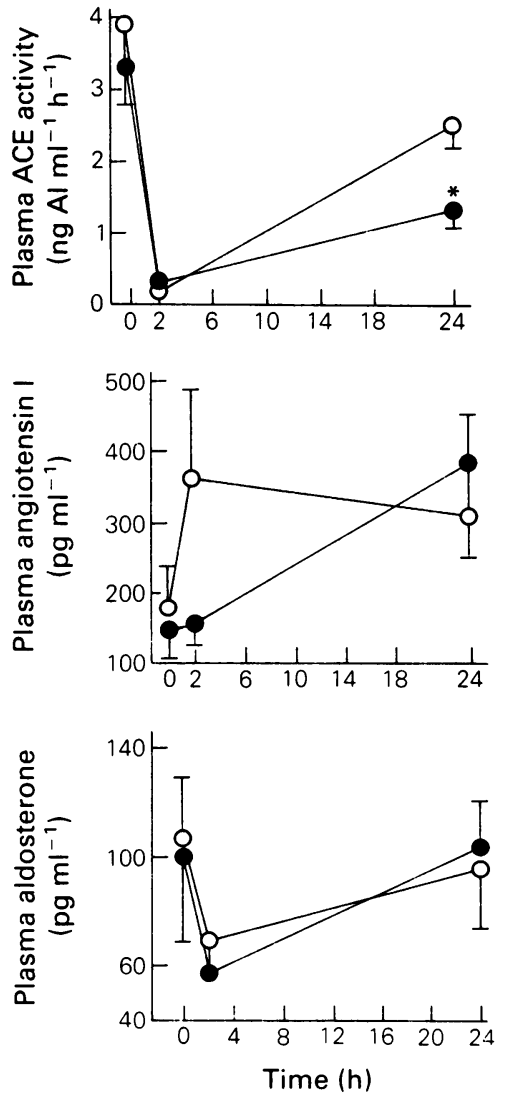

Figure 3 Mean ( \pm s.e. mean) plasma ACE, angiotensin $I$ and aldosterone levels in two age groups $(O$, young, $\bullet$ elderly) following pentopril administration ( ${ }^{*} P<0.05$ between two age groups).

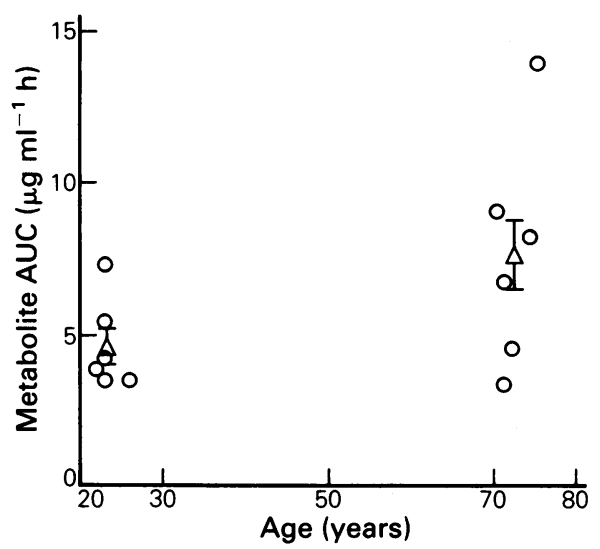

Figure 4 Interindividual variability (mean \pm s.e. mean) in AUC of metabolite in two age groups following pentopril administration. ( $O$ individual AUC, $\triangle$ mean AUC).

phase to total AUC is small.In any event, the general observation of increased AUC in elderly probably indicates decreased clearance of the metabolite, since $F$ and $f_{m}$ are not changed to any appreciable extent (Eq. 2). The lack of change of terminal half-life in the presence of increased AUC, hence, suggests a simultaneous decrease in volume of distribution $(V)$ with ageing. Although any changes in $V$ cannot be calculated directly in this study, such a decrease in $V$ of hydrophillic drugs in elderly has been reported (Antal et al., 1981).

The mean (s.d.) inulin clearance (GFR) in young subjects was $87.6(29.8) \mathrm{ml} \mathrm{min}^{-1}$, while 


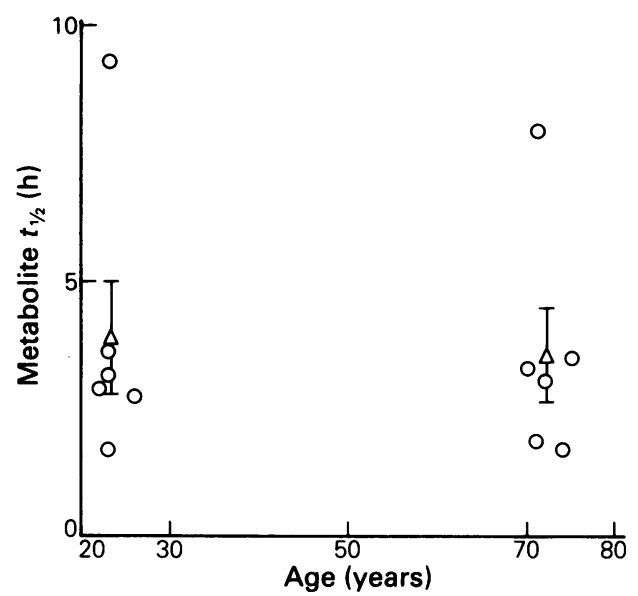

Figure 5 Interindividual variability (mean \pm s.e. mean) in terminal half-life of metabolite in two age groups following pentopril administration. ( $O$ individual $t_{1 / 2}, \Delta$ mean $\left.t_{1 / 2}\right)$.

elderly subjects it was somewhat smaller, 65.8 (27.0) $\mathrm{ml} \mathrm{min}^{-1}$. Consistent with the decreased kidney function in elderly, the renal clearances for both pentopril and metabolite decreased significantly ( $47 \%$ to $43 \%$, respectively). Since pentopril is primarily hydrolyzed in vivo to form the active metabolite and only about $20 \%$ is excreted unchanged in urine, the decreased renal clearance of pentopril did not cause any appreciable change in its systemic clearance, hence, no change in AUC. In contrast, the active metabolite is excreted primarily by the kidney, and decreased $C L_{R}$ with age would result in a decreased systemic clearance and, therefore, an increased AUC of the metabolite.

Renal clearance of both pentopril and the active metabolite decreased linearly with inulin clearance (Figure 6). The correlation coefficient, however, was low $(r=0.65, P<0.001)$ probably because of associated secretory contribution to the renal elimination process for these compounds (Rakhit et al., 1987).

Pharmacodynamic measurements of the reninangiotensin system were consistent with the increased plasma metabolite concentrations in that the plasma converting enzyme inhibition persisted to some extent in the elderly subjects even at $24 \mathrm{~h}$, unlike in the young volunteers $(P=$ 0.015). Angiotensin I and aldosterone levels.

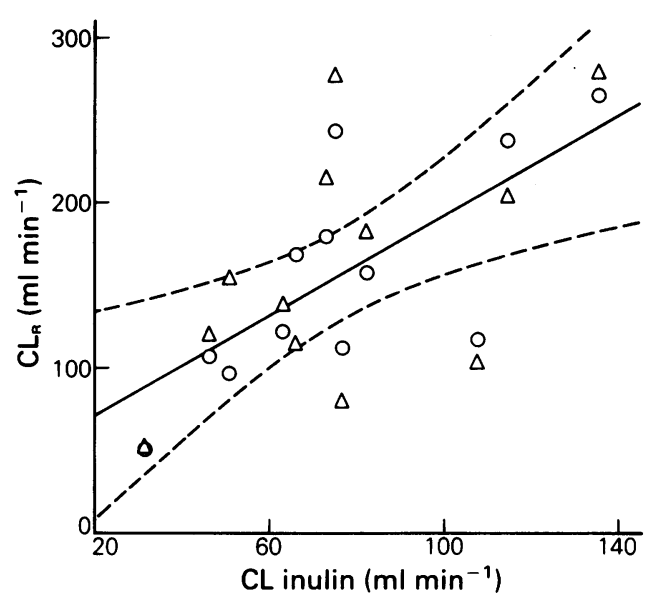

Figure 6 Changes in renal clearance with inulin clearance. The solid line represents the best fitted regression line $(y=1.53 x+40.6)$ while the broken lines represent $95 \%$ confidence interval around the mean regression line. $O$ pentopril, $\Delta$ metabolite.

however, did not show any statistically significant differences at 2 or $24 \mathrm{~h}$ between two age groups. Since these measurements were performed only at two post-dose time points ( 2 and $24 \mathrm{~h}$ ), no attempt was made to correlate them with plasma metabolite levels.

In conclusion, the results of the study suggest that in spite of a decrease in renal clearance of pentopril in the elderly subjects, the plasma concentration-time profile for pentopril remains almost unchanged with ageing. The AUC of active metabolite, however, appeared to increase with age consistent with its decreased renal clearance. The inter-subject variability of AUC in elderly was significantly higher than the younger group. The elimination half-life, however, did not change for either pentopril or active metabolite on ageing. Because of large variability in the AUC of the active metabolite, no definite dosing correction can be recommended based on pharmacokinetic behaviour. but greater caution may be needed in dose selection for the elderly population. Because the half-life $(3.6$ is $3.9 \mathrm{~h})$ of the active metabolite did not change with age. no substantial difference in the extent of drug accumulation is anticipated in elderly subjects compared with young.

\section{References}

Antal, E. K. \& Kramer, P. A. (1981). Theophylline pharmacokinetics in advanced age. Br. J. clin. Pharmac., 12, 637-645.
Chen. D. S. Brunner. H. R. \& Waeber. B. (1984). Invitro response of plasma angiotensin converting enzyme to precursors and active forms of convert- 
ing enzyme inhibitors. Curr. Ther. Res., 35, 253262.

Crooks, J. (1983). Pharmacokinetics in the elderly. In Handbook of clinical pharmacokinetics, eds Gibaldi, M. \& Prescott, L. Section II, pp. 169-187. New York: Adis.

Greenblatt, D. J., Divoll Allen, M., Locknisar, A., Harmatz, J. S. \& Shader, R. I. (1979). Lorazepam kinetics in the elderly. Clin. Pharmac. Ther., 26, 103-113.

Greenblatt, D. J., Divoll, M., Harmatz, J. S., MacLaughlin, D. S. \& Shader, R. I. (1981). Kinetics and clinical effects of flurazepam in young and elderly noninsomniacs. Clin. Pharmac. Ther., 30, 475-486.

Greenblatt, D. J., Divoll, M., Harmatz, J. S. \& Shader, R. I. (1980). Oxazepam kinetics: effects of age and sex. J. Pharmac. exp. Ther., 215, 86-91.

Jacot des Combes, B., Turini, G. A., Brunner, H. R., Porchet, M., Chen, D. S. \& Sen, S. (1983). CGS 13945: a new orally active angiotensin converting enzyme inhibitor in normal volunteers. $J$. cardiovasc. Pharmac., 5, 511-516.

Klotz, U. \& Muller-Seydlitz, P. (1979). Altered elimination of desmethyl-diazepam in the elderly. $\boldsymbol{B r}$. $J$. clin. Pharmac., 7, 119-120.

Lamy, P. P. (1982). Comparative pharmacokinetic changes and drug therapy in an older population. $J$. Am. Geriatr. Soc., 30, 511-519.

Rakhit, A., Hurley, M. E., Tipnis, V., Coleman, J., Rommel, A. \& Brunner, H. R. (1986). Pharmacokinetics and pharmacodynamics of pentopril, a new angiotensin converting enzyme inhibitor in humans. J. clin. Pharmac., 26, 156-164.

Rakhit, A., Kochak, G. M., Tipnis, V. \& Hurley, M. E. (1987). Inhibition of renal clearance of furosemide by pentopril, an angiotensin converting enzyme inhibitor. Clin. Pharmac. Ther., 41, 580-586.

Rakhit, A. \& Tipnis, V. (1984). Liquid chromatographic determination of an angiotensin converting enzyme inhibitor, CGS 13945, and its active metabolite (CGS 13934) in plasma. Clin. Chem., 30, 1237-1239.

Reidenberg, M. M. (1982). Drugs in the elderly. Med. Clin. North Am., 66, 1073-1078.

Tipnis, V. \& Rakhit, A. (1985). Determination of pentopril, an angiotensin converting enzyme inhibitor, and its active metabolite in urine. $J$. Chromatogr. (Biomed. Appl.), 345, 396-401.

(Received 10 November 1986, accepted 30 April 1987) 